\section{Research on mechano growth factor: its potential for optimising physical training as well as misuse in doping}

\section{G Goldspink}

Mechano growth factor can produce rapid increases in muscle and strength, giving it considerable therapeutic and doping potential

$\mathrm{T}$ he sequencing of the human genome showed that there are only about 40000 genes. However, there are many more proteins. This is because some genes are spliced to produce different protein/peptides which usually have different biological functions. Combining physiological and molecular biology methods made it possible for our team to identify and characterise a local muscle growth/repair factor (MGF). This we found is derived from the insulin-like growth factor I (IGF-I) gene by alternative splicing, but, owing to a reading frame shift, MGF has a unique C-terminal peptide. After resistance exercise, the IGF-I gene is spliced towards MGF which "kick starts" hypertrophy and repair of local muscle damage by activating the muscle stem cells as well as anabolic processes. Interestingly, loss of muscle mass in old age and in certain diseases is associated with an impaired ability to express MGF. In these conditions it seems that the muscle stem (satellite) cell pool is not adequately replenished.

\section{CLONING OF MGF AND OTHER HUMAN MUSCLE IGF-I SPLICE VARIANTS}

For some time it has been apparent that muscle mass and strength must be under the control of local growth factors because if one exercises a particular muscle, it is that muscle and not all the muscles of the body that undergo hypertrophy. A little over 10 years ago, our group set out to clone the factor(s) that are involved in autocrine regulation of muscle mass. For this purpose we needed to have an animal model in which we could make muscle grow rapidly. Previous work had shown that the tibialis anterior muscle in the mature rabbit, when held in the stretched position by plaster cast immobilisation combined with low voltage electrical stimulation, increased in mass by $35 \%$ in just over a week. ${ }^{1}$ It was known that muscles adapt to a new functional length by adding sarcomeres in series at the ends of the existing myofibrils. However, if muscles are also subjected to electrical stimulation, they increase in girth as well as length. Total RNA in these muscles was found to increase by about four times within a couple of days. We also studied specific messenger RNAs using a technique known as differential display and detected an mRNA that was expressed in exercised but not in resting muscles. ${ }^{2}$ This was converted into cDNA and sequenced, and the genome database showed that it was derived from the IGF-I gene. This local type of IGF-I we called mechano growth factor (MGF) as it was expressed in response to mechanical stimuli and because it has a different downstream (C-terminal) sequence from the liver or systemic types of IGF-I. From physiological experiments it became apparent that the muscle forms of IGF-I have different functions and that in the case MGF its unique C-terminal peptide has a special function of activating and replenishing the muscle stem (satellite) cell pool. As with the central nervous system, skeletal muscle is a post-mitotic tissue. Therefore there has to be an effective local cellular repair mechanism otherwise cell death will ensue. The extra nuclei required for growth and repair come from the muscle stem (satellite) cells fusing with the muscle fibres. This is also one of the early events in the hypertrophy process. MGF is responsible for replenishing the pool of muscle stem cells, ${ }^{34}$ and this provides the means by which strength adaptation occurs after exercise and/or local muscle damage.

\section{SPLICING OF THE IGF-I GENE IN RESPONSE TO EXERCISE AND HORMONES}

Previous research had shown that resistance exercise which results in muscle hypertrophy is associated with an increase in IGF-I expression. ${ }^{256}$ However, these studies failed to distinguish between the different types of IGF-I. As mentioned above, the way MGF was discovered was by studying the RNA transcript of exercised and non-exercised muscle. ${ }^{2}$ Shortly after this, the group of Ken Baldwin and Greg Adams in the United States ${ }^{7}$ showed that MGF is expressed earlier than IGF-IEa in response to exercise. Using specific primers (gene probes), we measured the mRNA concentrations of MGF and IGF-IEa using quantitative polymerase chain reaction mechanically in overloaded rodent muscle $e^{8}$ as well as in human volunteers in which muscle biopsy specimens were taken 2.5 hours after a single bout of high intensity exercise of knee extensor muscles. ${ }^{9}$ In young muscle, MGF mRNA concentrations were significantly increased as a result of resistance exercise, but no significant change was observed in older muscle when subjected to the same degree of mechanical overload. However, elderly male volunteers when given growth hormone combined with exercise training produced increased concentrations of $\mathrm{MGF}^{10}$ which could be correlated with increased muscle cross sectional area as determined from computed tomography scans. Figure 1 shows the way the IGF-I gene is spliced after exercise and in response to hormones.

It was noted that in exon 5 of MGF in the human there is a 49 base insert ( 52 in the rat) which results in a reading frame shift. Amino acids are coded for by triplets of bases. As the exon 5 insert is not a multiple of 3, the downstream peptide sequence of MGF is different from that of the other kinds of IGF-I. This region has important functional consequences as the carboxy peptide of some IGF-I isoforms is involved in the recognition of the specific binding proteins that stabilise these growth factors. At least two forms of systemic IGF-I are expressed by muscle even at rest. However, it is apparent that in response to exercise and/or damage, MGF is expressed locally and that it has a dual action. This includes activating the muscle stem cell pool through its Cterminal domain (encoded in exons 5 and 6) and increasing anabolic effects as the result of its IGF-I receptor binding domain (encoded in exons 3 and 4), which all the IGF-I genes possess.

\section{GENE TRANSFER AND ENHANCEMENT OF MUSCLE MASS AND STRENGTH}

One of the methods we used to establish the biological action of MGF was to engineer a gene into which its cDNA was inserted into a vector. To our 


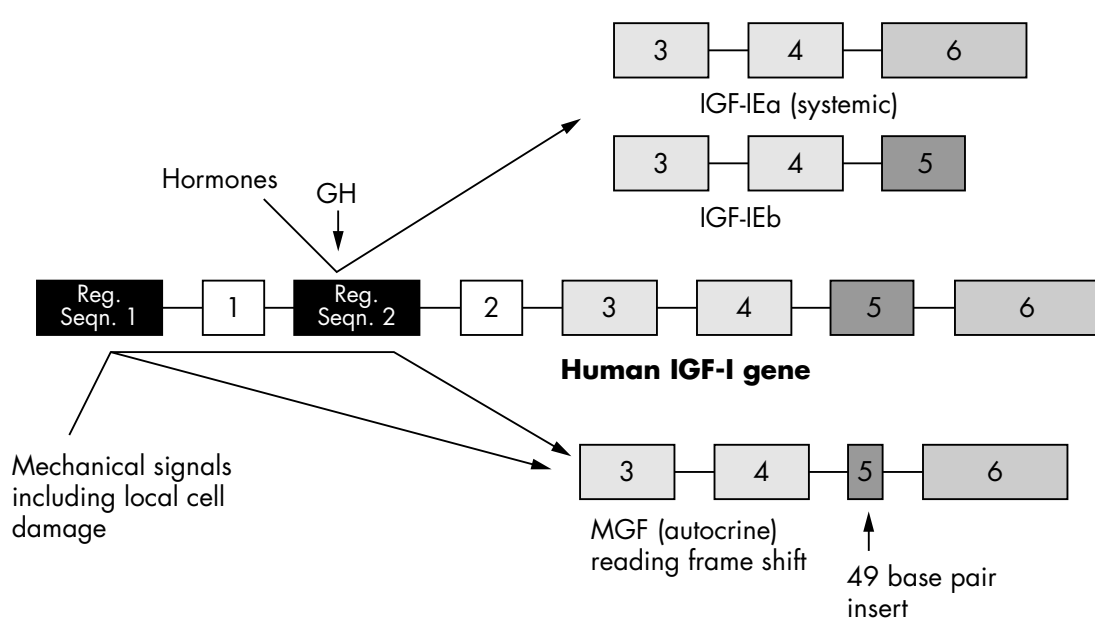

Figure 1 Splicing of the insulin-like growth factor (IGF) gene to produce different forms of IGF-I in human muscle. Mechano growth factor (MGF) is produced locally in response to exercise and it differs from the two systemic types of IGF-I as the 49 base insert in the exon creates a reading frame shift so that the downstream or C-terminal peptide sequence is different. This unique peptide has been found to be involved in activating the muscle stem cells and to "kick start" the tissue repair and/or hypertrophy processes. In the elderly, who are growth hormone (GH) deficient, there is an improvement in MGF expression when administration of recombinant human $\mathrm{GH}$ is combined with exercise. Reg Seqn, Regulatory sequence.

surprise a single intramuscular injection into a mouse muscle resulted in a $25 \%$ increase in mean muscle fibre cross section area within three weeks. ${ }^{11}$ Similar experiments have been carried out using the systemic or liver type of IGF-I in an adenoviral vector under the control of a muscle regulatory sequence. However, this took four months to produce a $15 \%$ increase and is probably due to the anabolic effect of IGF-I, which is common to all the splice variants. ${ }^{12}$ The use of the DNA of IGF-I and particularly MGF is therefore a prime candidate for gene doping for enhancement of athletic performance. This presents the anti-doping agencies with a challenge, as the range of vectors available for use in engineering these genes enable them to be designed so that the gene product can be delivered locally or systemically and also so that they can be switched on and switched off after they have been introduced into the body. Our research unit is using the extremely sensitive and specific reverse transcriptase polymerase chain reaction to amplify a vector and/or the enhancer cDNA as a means of detecting gene doping. We also know that MGF as well as IGF-I exist as class I and class 2 isoforms and that the ratios of these in serum change if they are introduced as the peptide or by gene transfer. Therefore there is the possibility of detecting the misuse of these strength generating substances even if delivered in the form of "gene doping".

\section{ACKNOWLEDGEMENTS}

The work described in this Review was supported by the Wellcome Trust, Action Research, the International Olympic Games WADA committee.

Br J Sports Med 2005;39:787-788.

doi: $10.1136 /$ bjsm.2004.015826

Correspondence to: Professor Goldspink, Department of Surgery, Royal Free and University College Medical School, Hampstead Campus, Rowland Hill Street, London NW3 2PF, UK; g.goldspink@medsch.ucl.ac.uk

Competing interests: none declared

\section{REFERENCES}

1 Goldspink G, Scutt A, Loughna P, et al. Gene expression in skeletal muscle in response to mechanical signs. Am J Physiol

2 Yang SY, Alnaqeeb M, Simpson $\mathrm{H}$, et al. Cloning and characterisation of an IGF-I isoform expressed in skeletal muscle subjected to stretch. J Muscle Res Cell Motil 1996;17:487-95.

3 Yang SY, Goldspink G. Different roles of the IGFIEc peptide (MGF) and mature IGF-I in myoblast 1992;262:R326-63. proliferation and differentiation. FEBS Lett 2002;522:156-60.

4 Hill M, Goldspink G. Expression and splicing of the insulin-like growth factor gene in rodent muscle is associated with muscle satellite (stem) cell activation following local tissue damage. J Physiol 2003;549:409-18.

5 Yan Z, Biggs RB, Booth FW. Insulin-like growth factor immunoreactivity increases in muscle affer acute eccentric contractions. J Appl Physiol 1993;74:410-14.

6 Czerwinski SM, Martin JM, Bechtel PJ. Modulation of IGF mRNA abundance during stretch-induced skeletal muscle hypertrophy and regression. J Appl Physiol, 1994;76:2026-30

7 Haddad F, Adams GR. Selected contribution: acute cellular and molecular responses to resistance exercise. J Appl Physiol 2002; 93:394-403.

8 Owino V, Yang SY, Goldspink G. Age-related loss of skeletal muscle function and the inability to express the autocrine form of insulin-like growth factor-1 (MGF) in response to mechanical overload. FEBS Lett 2001;505:259-63.

9 Hameed M, Orrell RW, Cobbold $M$, et al. Expression of IGF-I splice variants in young and old human skeletal muscle after high resistance exercise. J Physiol 2003;547:247-54.

10 Hameed $M$, Lange $\mathrm{KH}$, Andersen JL, et al. The effect of recombinant human growth hormone and resistance training on IGF-I mRNA expression in the muscles of elderly men. J Physiol 2004:555:231-40.

11 Goldspink G, Yang SY. Method of treating muscular disorders. United States Patent. Paten No US 6,221,842 B1, Apr 24, 2001.

12 Barton-Davis E, Shoturma DI, Musaro A, et al. Viral mediated expression of insulin-like growth factor-I blocks the aging-related loss of skeletal muscle function. Proc Natl Acad Sci USA 1998;95:15603-7.

\section{COMMENTARY}

The control of muscle growth is an important area of research in clinical and sports medicine. The team lead by Geoff Goldspink in London have made a significant contribution to the characterisation and function of growth factors in skeletal muscle. This leader is a summary of their work to date. It details the regulatory control and biological functions of spliced variants of the IGF-I gene and the potency and mechanism of action of the protein products. Genuine therapeutic potential is much in evidence from this work, but with athletes ever more informed of the potential of gene doping the article also serves to remind us of the challenges that lie ahead if we are to tackle "gene doping" for performance gain.

P Jakeman

Department of Physical Education and Sport Sciences, University of Limerick, Limerick, Ireland; phil.jakeman@ul.ie 
Overuse tendinopathies

\section{Matrix metalloproteases: a role in overuse tendinopathies}

\section{Magra, N Maffulli}

The balance between matrix metalloproteases and their inhibitors is important in maintaining healthy tendons

$\mathrm{T}$ endinopathy is a broad term used to describe disorders in and around tendons, with absence of inflammatory cells and a poor healing response, demonstrated by collagen fibrils separated from each other lengthwise and disrupted in cross section. Tendinitis, tendinosis, and paratenonitis are all examples of tendinopathy. ${ }^{1}$

\section{MATRIX METALLOPROTEASES (MMPS) AND TISSUE INHIBITORS OF METALLOPROTEASES (TIMPS)}

MMPs, a family of zinc and calcium dependent endopeptidases active at a neutral $\mathrm{pH}$, are involved in the remodelling of extracellular matrix (ECM) through their broad proteolytic capability. ${ }^{2}$ Degradation of collagen in tendon ECM is initiated by MMPs. ${ }^{3}$ Twenty three human MMPs have been identified, ${ }^{2}$ with a wide range of extracellular substrates (table 1). ${ }^{45}$ MMPs can be subdivided into four main groups: collagenases, which cleave native collagen types I, II, and III; gelatinases, which cleave denatured collagens and type IV collagen; stromelysins, which degrade proteoglycans, fibronectin, casein, collagen types III, IV, and V; membranetype MMPs. ${ }^{5}$

The activity of MMPs is inhibited reversibly by TIMPs in a non-covalent fashion in a $1: 1$ stoichiometry. ${ }^{5}$ There are four types of TIMP: TIMP1, TIMP2, TIMP3, and TIMP4. ${ }^{5}$ The balance between the activities of MMPs and TIMPs regulates tendon remodelling, and an imbalance produces collagen disturbances in tendons. ${ }^{6}$

\section{ROLE OF MMPS AND TIMPS IN TENDINOPATHY}

MMP3 may play a major role in regulation of tendon ECM degradation and tissue remodelling. An increased expression of MMP3 may be necessary for appropriate tissue remodelling and prevention of tendinopathic changes. ${ }^{7}$ The timing of MMP3 production is probably also critical in this process. ${ }^{7}$ MMP 3 and TIMP1, TIMP2, TIMP3 and TIMP4 are downregulated in tendinopathic ten- dons. $^{78}$ Decreased MMP3 expression may therefore lead to tendinopathic changes in tendons. The expression of MMP2 can be upregulated in Achilles tendinopathy, ${ }^{8}$ although Ireland et $\mathrm{al}^{7}$ showed no such upregulation in tendinopathic Achilles tendon. However, Ireland et al used autopsy materials as control tissue, whereas Alfredson et $a l^{8}$ used clinically normal looking tendon tissue in the same tendinopathic tendon. Also, interindividual variations could have produced different results. Physical exercise can influence local MMP and TIMP activities in human Achilles tendon ${ }^{9}$ with a pronounced increase in local levels of pro-MMP9 after exercise. MMP9 may well have a role in a potential inflammation reaction in human Achilles tendon induced by intensive exercise. Also, exercise causes a rapid increase in serum MMP9, ${ }^{10}$ a probable result of increased leucocytes in the circulation. ${ }^{11}$

Complete tears of the rotator cuff show no significant increase in MMPl mRNA expression, ${ }^{12}$ although the actual activity of MMPl may be upregulated, with downregulation of MMP2 and MMP3 activity. ${ }^{3}$ In animal models, the expression of MMP2 at the edges of an acute tear in the supraspinatus tendon is strongest at two weeks, and gradually reduces at three and six weeks, ${ }^{13}$ suggesting that MMP2 degrades ECM at the tendon edges and reparative tissue. ${ }^{13}$ TIMP1 is not present in normal tendons, but, after acute tears of the supraspinatus tendon, it is expressed in the tendon edges for two weeks. ${ }^{13}$ By six weeks after TIMP1, implying that TIMP1 may inhibit excessive degradation of ECM by MMP2. ${ }^{13}$ Contrary to the above findings, levels of TIMPl are higher in normal than tendinopathic patellar tendon, ${ }^{14}$ with a greater expression of MMP1 and suppressed expression of TIMP1 in tendinopathic patellar tendons. ${ }^{14}$ This lack of TIMPI activity in tendinopathic tendon perhaps causes a shift in the delicate balance in favour of greater collagenase activity, which would suggest that tendinopathy may be a disthe tear, there is no expression of order in healing of tendon with abnormal cellular responses to injury or repetitive stress which leads to tendon dysfunction, and may result in rupture. Although Choi et al ${ }^{13}$ showed increased expression of TIMPl two weeks after an acute supraspinatus tendon tear, that study was performed on an animal model, and it focused on the relation between MMP2 and TIMP1. Thus TIMPl may be downregulated in chronic tendinopathy and upregulated in acute tears.

The expression of MMP3, TIMP2, TIMP3, and TIMP4 mRNA is decreased in torn rotator cuff tendons. ${ }^{12}$ MMP3 may therefore play a role in the normal maintenance and remodelling of the rotator cuff tendon, and a decrease in normal MMP3 activity may represent a failure of normal matrix remodelling and maintenance. ${ }^{3}$ Also, MMP13 is upregulated at the mRNA and protein level in patients with complete tears of rotator cuff tendons. ${ }^{12}$

\section{DOES THE TYPE OF STRESS CHANGE MMP EXPRESSION?}

In an animal model, increased fluid flow produced upregulation of the genes for MMPl and MMP3. ${ }^{15}$ Thus, shear stress on tenocytes may potentially contribute to tendinopathy through the action of MMPs and cyclo-oxygenase II. $^{15}$ However, stress deprivation has been shown to upregulate MMPl expression in tenocytes in an animal model. ${ }^{16}$ Increasing the cyclic strain frequency totally eliminated MMPI mRNA expression at low amplitude strain levels. ${ }^{16}$ Also, when a static tensile load is applied to rat tail tenocytes, MMPI mRNA expression is inhibited in a dose dependent manner. ${ }^{17}$ Thus the type of force may influence the expression of MMP1: shear forces upregulate MMP1, ${ }^{15}$ whereas cyclical strain and static tensile loads downregulate MMP $1 .{ }^{16} 17$

\section{RELEVANCE FOR CLINICIANS}

The clinical applications of MMPs in the treatment of various orthopaedic conditions, including tendinopathies, are constantly being explored. Multiple steps in their regulation may offer potential targets at which future drug therapy may be aimed. Such drugs, which will have inhibitory activity against specific MMPs, will need to undergo stringent testing for absorption, bioavailability, metabolism, and excretion before the treatment is clinically approved. Although the discovery of specific, synthetic, orally active MMP inhibitors is still in its early days, they will have a huge impact in the management of tendinopathies, despite varying opinions on the best MMP to inhibit. ${ }^{4}$ The 
Table 1 The main components of the matrix metalloprotease (MMP) family

\begin{tabular}{|c|c|c|c|}
\hline Name & Synonym & Degrades & Other actions \\
\hline MMP1 & $\begin{array}{l}\text { Collagenase-1 } \\
\text { Interstitial collagenase } \\
\text { Fibroblast collagenase }\end{array}$ & $\begin{array}{l}\text { Collagens type III (preferentially), I, and II } \\
\text { Collagens type VII, VIII, and X }\end{array}$ & \\
\hline MMP2 & $\begin{array}{l}72 \mathrm{kDa} \text { gelatinase } A \\
72 \mathrm{kDa} \text { type IV gelatinase }\end{array}$ & $\begin{array}{l}\text { Gelatin, collagens type IV, V, VII, X, and XI } \\
\text { Fibronectin, elastin, proteoglycans }\end{array}$ & Synergistic with MMP1 \\
\hline MMP3 & $\begin{array}{l}\text { Stromelysin-1 } \\
\text { Transin, proteoglycanase } \\
\text { Procollagen activating factor }\end{array}$ & $\begin{array}{l}\text { Proteoglycans, laminin, fibronectin, gelatin } \\
\text { Collagens III, IV, V, and IX } \\
\text { Core protein of cartilage proteoglycans }\end{array}$ & $\begin{array}{l}\text { Broad substrate specificity } \\
\text { Activates pro-MMPs }\end{array}$ \\
\hline MMP7 & $\begin{array}{l}\text { Matrilysin } \\
\text { Pump-1 } \\
\text { Small uterine proteinase }\end{array}$ & Gelatin, proteoglycans, fibronectin, elastin, casein & Activates pro-MMP1 \\
\hline MMP8 & Neutrophil collagenase & $\begin{array}{l}\text { Collagens type I (preferentially), II, and III } \\
\text { Aggrecan }\end{array}$ & \\
\hline MMP9 & $\begin{array}{l}92 \mathrm{kDa} \text { gelatinase- } \mathrm{B} \\
92 \mathrm{kDa} \text { type IV gelatinase }\end{array}$ & $\begin{array}{l}\text { Collagens type IV, V, X, XI } \\
\text { Gelatin }\end{array}$ & \\
\hline MMP10 & $\begin{array}{l}\text { Stromelysin-2 } \\
\text { Transin-2 }\end{array}$ & Gelatin, fibronectin, collagens type III, IV, and V & Activates pro-MMPs \\
\hline MMP11 & Stromelysin-3 & Aggrecan, fibronectin, laminin & \\
\hline MMP12 & Macrophage metalloelastase & $\begin{array}{l}\text { Elastin, collagen types I and IV, aggrecan, fibronectin, } \\
\text { laminin, entactin, gelatin type I, vitronectin, fibrillin }\end{array}$ & \\
\hline MMP13 & Collagenase-3 & $\begin{array}{l}\text { Collagens type II (preferentially), I, and III } \\
\text { Gelatin }\end{array}$ & \\
\hline
\end{tabular}

potential of drugs that decrease MMP activity to basal levels and therefore reduce excessive tissue degradation will have a profound impact on the management of tendinopathies in the near future. The two principal ways to decrease concentrations of MMPs are inhibition of enzyme activity and inhibition of enzyme synthesis. ${ }^{4}$ It is uncertain whether administration of exogenous TIMPs will be useful therapeutically. However, increasing the local production of TIMPs may be an alternative therapeutic option. ${ }^{4}$

An inhibitor of MMPs, aprotinin, has been used in musculoskeletal practice to decrease bleeding from scoliosis surgery. ${ }^{18}$ We and other authors have used it peritendinously in the management of Achilles ${ }^{19}$ and patellar ${ }^{20}{ }^{21}$ tendinopathy, with good middle term success compared with peritendinous injections of corticosteroids. We are also aware of further studies being conducted using aprotinin (http://www.users.bigpond. com/msn/johnorchard/aprotinin_study. htm).

\section{CONCLUSIONS}

Tendon matrix is not static; it is constantly remodelled, with higher rates of turnover at sites exposed to high level strain. MMPs and their inhibitors are crucial to ECM remodelling, and a balance exists between them in normal tendons. Alteration of MMP and TIMP expression from basal levels leads to alteration of tendon homoeostasis. Tendinopathic tendons have an increased rate of matrix remodelling, leading to a mechanically less stable tendon which is more susceptible to damage. Table 2 highlights the role played by various MMPs and TIMPs in the pathogenesis of tendinopathy. Current concepts on the role of MMPs

Table 2 Main roles of some matrix metalloproteases (MMPs) and tissue inhibitors of metalloproteases (TIMPs)

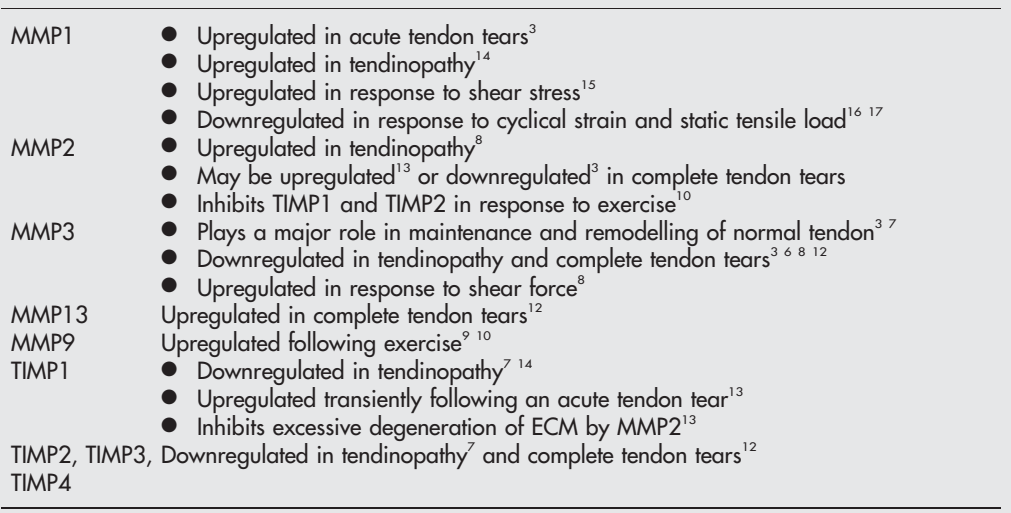

in tendinopathy have mostly been derived from in vitro or animal model studies, and may not accurately reflect the behaviour of MMPs in vivo. Also, clinical studies have numerous variables that may affect the outcome of results obtained, leading to conflicting results in some cases. More research is required to understand the complexities of interplay between the different MMPs and their inhibitors in the pathogenesis of tendinopathy to devise specific therapeutic strategies in these patients.

Br J Sports Med 2005;39:789-791. doi: 10.1136/bjsm.2005.017855

$\ldots \ldots \ldots \ldots \ldots$

\section{Authors' affiliations}

M Magra, N Maffulli, Department of Trauma and Orthopaedic Surgery, Keele University

School of Medicine, Stoke on Trent,

Staffordshire, UK

Correspondence to: Professor Maffulli, Department of Trauma and Orthopaedic Surgery, Keele University School of Medicine, Thornburrow Drive, Hartshill, Stoke on Trent ST4 7QB, Staffordshire, UK; osa14@keele.ac. uk

Competing interests: none declared

\section{REFERENCES}

1 Khan KM, Cook JL, Bonar F, et al. Histopathology of common tendinopathies. Update and implications for clinical management. Sports Med 1999:27:393-408.

2 Oblander SA, Somerville RPT, Apte SS. An update on metalloproteinases in the musculoskeletal system. Curr Opin Orthop 2003;14:322-8.

3 Riley GP, Curry V, DeGroot J, et al. Matrix metalloproteinase activities and their relationship with collagen remodelling in tendon pathology. Matrix Biol 2002;21:185-95.

4 Goupille P, Jayson MIV, Valat J, et al. Matrix metalloproteinases: the clue to intervertebral disc degeneration? Spine 1998;23:1612-26. 
5 Bramono DS, Richmond JC, Wietzel PP, et al. Matrix metalloproteinases and their clinical applications in orthopaedics. Clin Orthop 2004:428:272-85

6 Dalton S, Cawston TE, Riley GP, et al. Human shoulder tendon biopsy samples in organ culture produce procollagenase and tissue inhibitor of metalloproteinases. Ann Rheum Dis 1995;54:571-7.

7 Ireland D, Harrall R, Curry V, et al. Multiple changes in gene expression in chronic human Achilles tendinopathy. Matrix Biol $2001 ; 20$ : 159-69.

8 Alfredson $\mathrm{H}$, Lorentzon $\mathrm{M}$, Bäckman $\mathrm{S}$, et al. CDNA: arrays and real time quantitative PCR techniques in the investigation of chronic Achilles tendinosis. J Orthop Res 2003;21:970-5.

9 Koskinen SOA, Heinemeier KM, Olesen JL, et al. Physical exercise can influence the levels of matrix metalloproteinases and their inhibitors in tendon related connective tissue. J Appl Physiol 2004;96:861-4.

10 Koskinen SOA, Höyhtyä $M$, TurpeemnniemiHujanen $T$, et al. Serum concentrations of collagen-degrading enzymes and their inhibitors after downhill running. Scand J Med Sci Sports 2001;11:9-15.

11 McCarthy DA, Dale MM. The leucocytosis of exercise. A review and model. Sports Med 1988;6:333-63.

12 Lo IKY, Marchuk L, Hollinshead R, et al. Matrix metalloproteinase and tissue inhibitors of metalloproteinases mRNA are specifically altered in torn rotator cuff tendons. Am J Sports Med 2004;32:1223-9

13 Choi HR, Seiji K, Kazuyoshi H, et al. Expression and enzymatic activity of MMP-2 during healing process of acute supraspinatus tendon tear in rabbits. J Orthop Res 2002;20:927-33.

14 Fu SC, Chan BP, Wang W, et al. Increased expression of matrix metalloproteinase l (MMP-1) in 11 patients with patellar tendinosis. Acta Orthop Scand 2002;73:658-62.

15 Archambault JM, Elfervig-Wall MK, Tsuzaki M, et al. Rabbit tendon cells produce MMP-3 in response to fluid flow without significant calcium transients. J Biomech 2002;35:303-9.

16 Lavagnino M, Arnoczky SP, Tian T, et al. Effect of amplitude and frequency of cuylic tensile strain on the inhibition of MMP-1 mRNA expression in tendon cells: an in vitro study. Connect Tissue Res 2003;44:181-7.

17 Amoczky SP, Tian T, Lavagnino M et al. In situ tensile load modulates inhibition of MMP-1 expression in rat tail tendon cells in a dosedependant manner through a cytoskeletallybased based mechanotransduction mechanism. J Orthop Res 2004;22:328-33.

18 Cole JW, Murray DJ, Snider RJ, et al. Aprotinin reduces blood loss during spinal surgery in children. Spine 2003;28:2482-5.

19 Capasso G, Maffulli N, Testa V, et al. Preliminary results with peritendinous protease inhibitor injections in the management of Achilles tendinitis. J Sports Traumatol Rel Res 1993;15:37-43.

20 Capasso G, Testa V, Maffulli N, et al. Aprotinin corticosteroids and normosaline in the management of patellar tendinopathy in athletes: a prospective randomized study. Sports, Exercise and Injury 1997;3:111-15.

21 Aubin F, Javaudin L, Rochcongar P. Case reports of aprotinin in Achilles tendinopathies with athletes. Journal de Pharmacie Clinique 1997; 16:270-3. 